\title{
THE IMPACT OF THE CLASSROOM ENVIRONMENT ON THE TRANSITION FROM THE TRADITIONAL MODEL TO THE FLIPPED ClassRoom in A UNIT OPERATION COURSE
}

\author{
Clémence Fauteux-Lefebvre \\ Department of Chemical and Biological Engineering, University of Ottawa, Ottawa, Ontario, Canada \\ cfauteux@uottawa.ca
}

\begin{abstract}
The learning objectives of the Unit Operation course are to learn, understand and apply the operational and design principles of various separation units. For each unit, students must learn the process principles, how to apply mass and energy balances and how to use solving procedures in various contexts to design units, based on given parameters and operating objectives.

The main challenges for the students are to develop the general design skills and the necessary knowledge of the theory principles, with a deep understanding of the various concepts and procedures specific to each unit. The traditional format of the course leads students to solve problems mostly during their study time, while the help of the teacher is not direct. A flipped classroom approach would allow students to revise, explore and acquire significant part of the knowledge online or on their own rather than during the lectures and then to benefit from more efficient design problem-solving sessions. It, however, requires adaptation and engagement from both the students and the instructors for a successful learning experience.

In this course, the transformation is gradually implemented with the use of active learning classrooms and the development of a blended learning format of the course, to obtain an entirely flipped classroom. The access to active learning classrooms is one of the tools that could impact the quality of the flipped classroom organization, but also change the student's experience, and was the studied. Having the suitable space, tools and seating organization to easily work in team and share their work with the entire group efficiently could help them to be engaged and to develop these new skills. The assessment of the student's experience during the unit operations course in the active learning classroom showed that it promotes collaboration and it was appreciated by the majority of students, with a clear preference for this classroom over a traditional one for the various learning activities. It could then help reducing some obstacles to engage students in cooperative learning.
\end{abstract}

Keywords: Flipped classroom, Blended learning, Unit operation course, Chemical engineering, Classroom environment, Active learning classroom, Student engagement.

\section{INTRODUCTION}

Unit Operation is a core course in the Chemical Engineering degree. During this course, students learn how to design industrial equipment for evaporation, drying, humidification, absorption and stripping, distillation, liquid-liquid extraction, leaching and adsorption. These are processes for separation and purification of intermediary or final products and are critical in many chemical processes. It is a third-year course, which builds on knowledge and skills acquired by students during their previous semesters, such as solving mass and energy balances, understanding and using multi-phase thermodynamic equilibrium, applying mathematical methods, and solving heat transfer and transport phenomena problems.

The learning objectives of the Unit Operation course are therefore to learn, understand and apply the operational and design principles of various separation units. For each unit, students must learn or revise process principles (process function, unit types, advantages and disadvantages, mass transfer, thermodynamic equilibrium, etc.). Then, they must learn to apply mass and energy balances, understand adequate solving procedures and develop their solving skills with these principles in various contexts to design a unit, based on given parameters and operating objectives.

The main challenges for the students are to acquire the general design skills and the necessary knowledge specific to each unit with a deep understanding of the various concepts, equations and procedures. The traditional format of the course leads to introduce and explain the theory and concepts during lectures and to require from students to solve problems mostly during their study time, while the help of the teacher is not direct. Even with the use of tutorial sessions, this is therefore somehow contradictory with what are the expected learning outcomes. In addition, the course relies on many previous acquired skills by the 
students, and each individual student might require more or less revision before being able to apply them in a new context.

\subsection{Flipped Classroom Approach for Unit Operation Course}

A solution to address this gap between the instructional approach and the desired learnings is to modify the course toward a flipped classroom format. The flipped classroom approach is more and more used in science, technology, engineering, and mathematics (STEM) disciplines teaching as well as other disciplines, with the overall objectives, among others, of improving teaching/learning strategies and student learning experience, and reducing the gab between learning objectives and teaching methods [1]-[4]. The flipped classroom models and applications shown positive impact on both the performance and satisfaction of students, even if there is no model that fits all learner types, and if there are challenges associated to it [3], [5]-[8]. One of the challenges is the necessary paradigm shift from both the instructor and the students. A flipped classroom approach would allow students to revise, explore and acquire significant part of the knowledge online or on their own rather than in-class and then to benefit from more efficient design problem-solving sessions. However, to go from the traditional model where the teacher is leading the lectures to the full flipped classroom where students are more in charge of their learnings during the classes, it needs adaptation and time from both the teacher and the students.

For the instructor, it requires to involve a higher amount of time in the preparation prior to the course and to do a very detailed and proper preparation and course design [6], [8]. For the students it requires to adapt to a new teaching method, needing a profound engagement in the course and motivation, for an appropriate preparation prior to each class [3], [8], [9]. The flipped classroom course therefore has to meet learning objectives, but also needs to be aligned with learning expectations of students and their developing learning abilities.

Students have the abilities to be more engaged in their learning and to be more active in the classroom, but after few years of the traditional model, they also have to develop some additional learning skills. The course has to be properly designed to ensure that students reach the learning outcomes while gaining these new skills.

\subsection{Tools for Transition Toward the Flipped Classroom Approach}

While blended learning and flipped classrooms are two different concepts, the blended learning approach can be used in the context of the flipped classroom approach. In this case, the technologies are used to shift the content of the traditional lectures to a virtual environment with keeping face-to-face meetings for active learning methods.
For the purpose of this paper, the definition of the blended learning is the one used by University of Ottawa: "A blended course is designed such that some in-class time is substituted by equally meaningful online activities" [10]. The blended learning approach has numerous advantages such as offering flexibility, reaching a range of learner types, and keeping instructor contact, but it, however, should be well designed using appropriate tools to reach these goals [1], [7], [11], [12]. One of the keys for the success of a blended course is the availability and adequate use of teaching and communication tools. For the collaboration between students in both flipped classroom and blended learning approach [12], [13], the access to an adequate environment for cooperative learning should not be denied. The classroom physical organization is then a part of the teaching ecosystem and the teaching tools.

In this Unit Operation course, the transition from the traditional format to a flipped classroom is gradually implemented with the integration of problem-solving sessions during the lectures and the access and the use of an active learning classroom. The next step is the development of a blended format of the course, in which part of the lectures will be transferred to online activities and part of the lectures remained in face-to-face with problem-solving sessions with a final objective to obtain an entirely flipped classroom course.

During a semester, half of the lectures and all tutorials were given in active learning classrooms, which is organized for collaborative and cooperative learning with tables around which students sit and the instructor can move around to easily interact with each student. The other half of the lectures were given in a regular smallauditorium type classroom. The impact of the use of the active learning classroom was observed by the instructor and assessed through a survey distributed to the students. In this paper, a first analysis of the impacts of the classroom organization on the engagement of the students in problemsolving and group work during classes will be presented and discussed.

\section{METHODOLOGY}

\subsection{Learning outcomes and type of learning activities}

By completing the Unit Operations course, the students would be able to: 1) apply principles of mass transfer and equilibrium as well as material and energy balances to various unit operations to solve for unknown design parameters; 2) use knowledge for choosing the appropriate unit operation to achieve the process needs 3 ) solve various separation units for well-defined problems, using appropriate hand calculations or solving procedures and 4) design (i.e. determine the type of unit, dimensions, the operating parameters, etc.) a separation unit using 
appropriate numerical tools or solving procedures, in an illdefined context.

Currently, the learning activities are 1) regular lectures for the presentation of the theory principles and design procedures as well as for example demonstrations, 2) shortproblem to be solved by students in teams covering mostly the theory principles during the lectures, 3) in-depth analysis of examples by students in teamwork during lectures, 4) short quizzes during lectures, 5) long-problems to be solved by students in teams during tutorials and in assignments and 6) ill-defined design project to be done by students in teams. There are 24 lectures during the semester and 12 tutorials.

\subsection{Classroom Organization and Tools}

As mentioned, two different classrooms were used for this course. The active learning classroom was used for half of the scheduled lecture-type classes and all the tutorial sessions. This classroom has 8 rectangular tables placed around the room with one end on the wall. Each of the table can accommodate 9 students and has a mounted screen that can be used by the students or by the instructor. There is a desktop with the control panel and a computer for the instructor at the centre of the room, as well as two additional screens and 3 whiteboards.

The other half of the lecture-type classes happened in the small-auditorium type classroom. This classroom is organized with a screen and blackboards in the front of the class, and seats with a little table for each one to take notes.

The course was mostly organized in a manner that traditional lecture presentations were made in the smallauditorium type classroom, while more student-engaging activities were proposed in the active learning classroom. However, since the course is still in a transition phase, some traditional lecture presentation parts were given in the active learning classroom. Quizzes were done in both types of classroom.

\subsection{Survey Description}

A short survey was distributed to the students during the last class of the semester, in order to obtain their feedback regarding the impact of the classrooms on their learning experience during the course. This survey was divided in two parts. The part 1 sub objective was to investigate their preference between the two classrooms for various learning activities (quizzes, working on long problems, working on short problems, going through examples and regular lectures delivered by the instructor). The part $2 \mathrm{sub}$ objective was to obtain their opinion on the suitability of the classrooms for the various learning activities. 31 students out of the 47 registered for the course filled the survey.

\section{RESULTS AND DISCUSSION}

\subsection{Results from the Survey}

The distribution of the preferences between the two classrooms for the five main learning activities composing the lectures and the tutorial sessions is shown in Fig. 1. Students were asked which classroom they preferred between the two for each of the activities, or which one would they have been preferred in the case only one was used (this was the case only for long-problem-solving that was done uniquely in the active learning classroom).

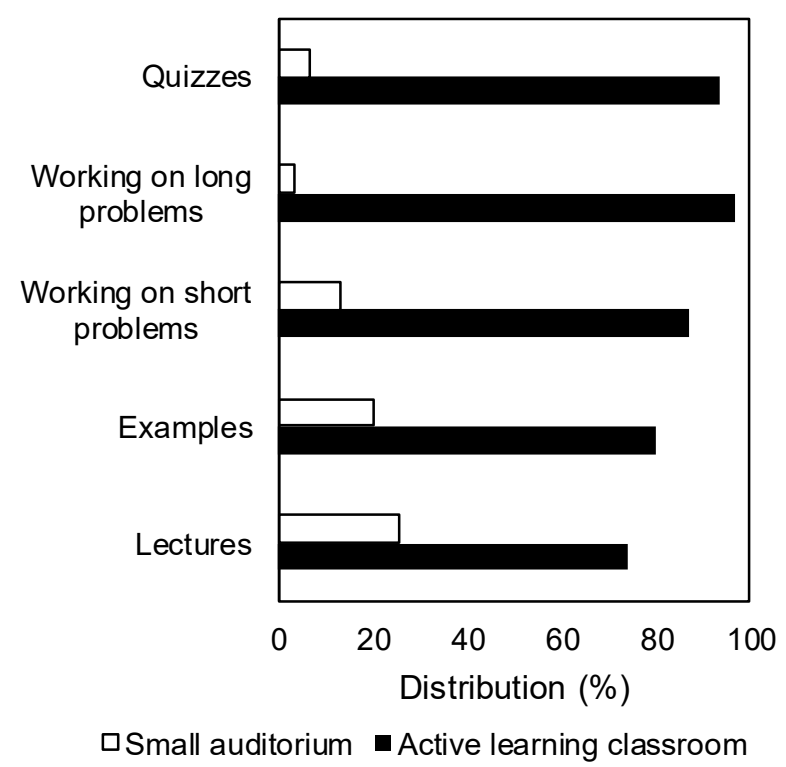

Fig. 1. Classroom preference of students-distribution for various learning activities.

In all the cases, the students preferred the active learning classroom, with preferences ranging from $74 \%$ to $94 \%$ depending on the learning activity. Although it was expected that students will prefer the active learning classroom for the teamwork and for problem-solving activities ("Working on long problems" and "Working on short problems"), the preference for the active learning classroom for lecture-type sessions was less anticipated. This classroom being designed to promote student-driven learning through collaboration and cooperation, it seems less appropriate for the traditional lecture-type teaching. The assessment of how suitable were the classroom from a student's perspective is then shown in Fig. 2. 


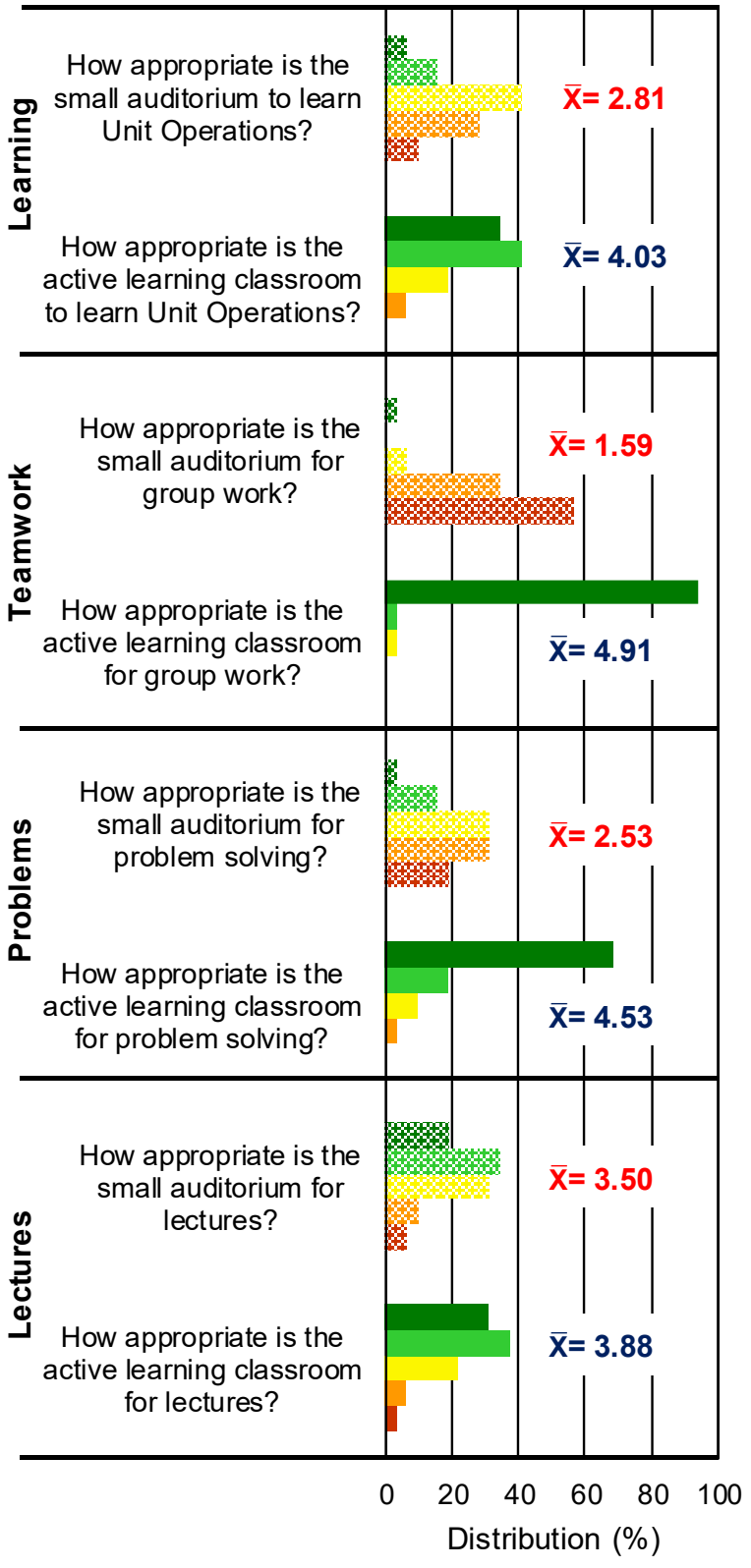

$\square$ (really appropriate)
$\square$ (a little appropriate)
$=3$ (neutral)
$=2$ (not really appropriate)
$\square 1$ (not appropriate)

Fig. 2. Student suitability assessment of the two different classrooms for various learning activities. The averages per activity and classroom are given, ranging from 5 (really appropriate) to 1 (not appropriate).

A closer look at the suitability and not just the preferences is important because the penchant for the active learning classroom could be related to the fact that the two classrooms were extreme opposites. An additional factor that might also have influenced the results is the schedule of the lectures in the small-auditorium type classroom versus the active learning classroom.

The results on the suitability of the classrooms are nevertheless well-aligned with the results on preferences. They are summarized in Table 1, with the percentage of the students finding the classroom appropriate for each learning activities. In all cases, the active learning classroom was found appropriate by a majority of the students, and it was the opposite for the small-auditorium type classroom.

Table 1: Percentage of students finding the classroom a little or really appropriate (4 or 5 scores) for various learning activities.

\begin{tabular}{|l|c|c|}
\hline $\begin{array}{l}\text { Learning } \\
\text { activities }\end{array}$ & $\begin{array}{c}\text { Active learning } \\
\text { classroom }\end{array}$ & $\begin{array}{c}\text { Small-auditorium } \\
\text { type classroom }\end{array}$ \\
\hline $\begin{array}{l}\text { Overall } \\
\text { learnings }\end{array}$ & $75 \%$ & $22 \%$ \\
\hline Teamwork & $97 \%$ & $3 \%$ \\
\hline $\begin{array}{l}\text { Problem } \\
\text { solving }\end{array}$ & $88 \%$ & $19 \%$ \\
\hline $\begin{array}{l}\text { Traditional } \\
\text { lectures }\end{array}$ & $69 \%$ & $53 \%$ \\
\hline
\end{tabular}

The results then showed that even if the suitability of the active learning classroom for lectures was less than for teamwork and problem-solving, students still found it appropriate for their learnings.

\subsection{Observations during the classes}

During the classes, the effect of the classroom environment was also perceivable from an instructor perspective. When students were asked to work on shortproblem-solving and to go through examples in teams, the sitting organization seemed to favour a natural collaboration and cooperation between them as well as to enhance their engagement. They were almost instantaneously going through the example and discussing it in small groups or trying to solve the problems with many interactions between students. In addition, and this is coherent with the student's assessment, the students seemed more engaged in the discussion while doing the lecture-type presentations in the active learning classroom. Finally, the direct access to each individual student was easier, facilitating discussion with teams or individuals during practice problems.

\section{CONCLUSIONS}

Some flipped classroom approach tools have been integrated into a Unit Operation course during a semester, with part of the lectures and all the tutorials given in an active learning classroom.

The student appraisal of the classrooms was assessed, and they had a preference for the active learning classroom, for all the tested indicators such as problem-solving and 
overall learning experience, and even the traditional lecture-type sessions.

The next stage for this course is to include blended learning and then to move toward a full flipped classroom. The subsequent step for the evaluation of the teaching methods is the assessment of the learnings and the development of the student skills in this new approach.

\section{Acknowledgements}

The blended course development is supported by the Funding Program of the Blended Learning Initiative of the University of Ottawa. The author acknowledges the support from the Teaching and Learning Support Service team, in both the blended course development and for support in the use of the classroom, namely Ms. Nancy Vézina, Mr. Jean-Pascal Beaudoin, Ms. Melissa Brasgold and Mr. Gilles Laberge. The author is indebted to $\mathrm{Mr}$. Mathieu Neil Tousignant for its work in the development of virtual learning tools.

\section{References}

[1] Paul Bazelais and Tenzin Doleck, "Blended learning and traditional learning: A comparative study of college mechanics courses," Education and Information Technologies, vol. 23, no. 6, pp. 2889-2900, 2018.

[2] Mario M. Valero, Maria Martinez, Francesc Pozo, and Eulàlia Planas, "A successful experience with the flipped classroom in the Transport Phenomena course," Education for Chemical Engineers, vol. 26, pp. 67-79, 2019.

[3] Gökçe Akçayır and Murat Akçayır, "The flipped classroom: A review of its advantages and challenges," Computers \& Education, vol. 126, pp. 334-345, 2018.

[4] Ralf Becker and Alvin Birdi, "Flipping the classroom: Old ideas, new technologies," International Review of Economics Education, vol. 29, pp. 1-5, 2018.

[5] Pablo Schwarzenberg, Jaime Navon, Miguel Nussbaum, Mar Pérez-Sanagustín, and Daniela Caballero, "Learning experience assessment of flipped courses," Journal of Computing in Higher Education, vol. 30, no. 2, pp. 237258, 2018.

[6] Isaiah T. Awidi and Mark Paynter, "The impact of a flipped classroom approach on student learning experience," Computers \& Education, vol. 128, pp. 269-283, 2019.

[7] Clem Herman, Rosaria Gracia, Lesley Macniven, Bernie Clark, and Geraldine Doyle, "Using a blended learning approach to support women returning to STEM," Open Learning: The Journal of Open, Distance and e-Learning, vol. 34, no. 1, pp. 40-60, 2019.

[8] David Evenhouse, Nimit Patel, Maria Gerschutz, Nick A. Stites, Jeffrey F. Rhoads, Edward Berger and Jennifer DeBoer, "Perspectives on pedagogical change: instructor and student experiences of a newly implemented undergraduate engineering dynamics curriculum," European Journal of Engineering Education, vol. 43, no. 5, pp. 664-678, 2018.

[9] Kris M. Y. Law, Shuang Geng, and Tongmao Li, "Student enrollment, motivation and learning performance in a blended learning environment: The mediating effects of social, teaching, and cognitive presence," Computers \& Education, vol. 136, pp. 1-12, 2019.

[10] University of Ottawa, "What is a blended course?," University of Ottawa - Teaching and Learning Support Service, 2019. [Online]. Available: https://tlss.uottawa.ca/site/what-is-a-blended-course.

[11] Xianlu Zeng, Caoming Yu, Ya Liu, Xin Hu, Qinglan Hao, Yongfu Jiang, Wei Dai, Kangda Zhang and Botao Teng, "The construction and online/offline blended learning of small private online courses of Principles of Chemical Engineering," Computer Applications in Engineering Education, vol. 26, no. 5, pp. 1519-1526, 2018.

[12] Hang Shu and Xiaoqing Gu, "Determining the differences between online and face-to-face student-group interactions in a blended learning course," The Internet and Higher Education, vol. 39, pp. 13-21, 2018.

[13] Robert A. Ellis, Abelardo Pardo, and Feifei Han, "Quality in blended learning environments - Significant differences in how students approach learning collaborations," Computers \& Education, vol. 102, pp. 90-102, 2016. 